\title{
Broad-Scale Assessments of Ecological Landscapes- Developing Methods and Applications
}

P ublic lands are subject to increasingly complex and widespread environmental stressors that transcend traditional management boundaries. To address these challenges, the U.S. Department of the Interior (DOI) Bureau of Land Management (BLM) is developing a Landscape Approach for managing multiple uses of public lands and sustained yield of their renewable natural resources. The BLM Landscape Approach incorporates multiscale information to quantify the effects of natural and human influences on natural resource conditions and trends. A primary goal of the approach is to identify opportunities for resource conservation, restoration, and development. By quantifying and synthesizing information across regions, the Landscape Approach is useful for identifying important ecological resources and quantifying the effects of environmental change that may not be evident at finer scales. Ecological resources can include important wildlife habitats and ecological communities, as well as pristine or unique areas that have high conservation potential.

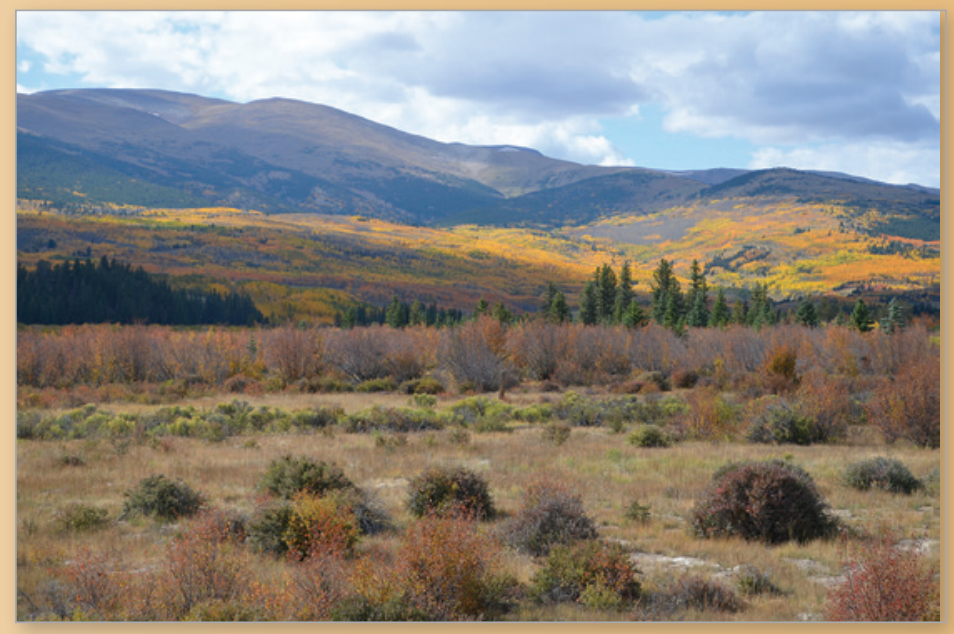

Aspen landscape near Fairplay, Colorado. Photograph by Tasha Carr, USGS, 2014.
The BLM Landscape Approach is closely aligned with the DOI's “A Strategy for Improving the Mitigation Policies and Practices of The Department of the Interior," also referred to as the Landscape-Scale Mitigation Strategy (Landscape Strategy). A primary objective of the DOI Landscape Strategy is to shift from project-level to broad-scale, science-based management that helps to avoid, minimize, and compensate for adverse effects to natural resources. The BLM Landscape Approach addresses the following key components outlined by the DOI Landscape Strategy: develop assessment methods that promote consistency in management decisions, identify ecological characteristics that promote ecosystem resilience under rapidly changing environmental conditions, and foster collaboration among land management agencies.

The BLM Landscape Approach and the DOI Landscape Strategy recognize the need for methods and tools to quantify

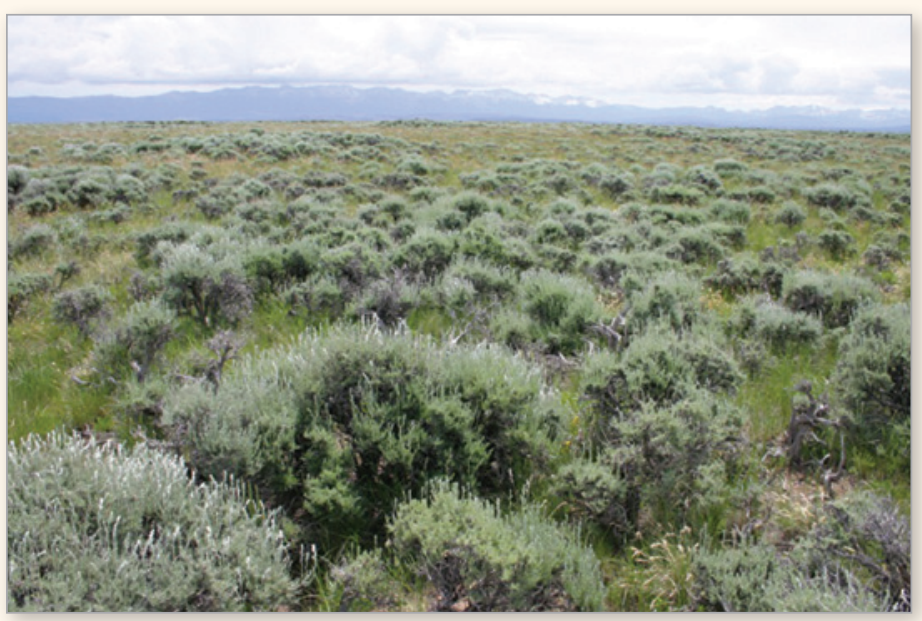

Sagebrush in Wyoming. Photograph by Cameron Aldridge, Colorado State University, 2010. landscape-level effects across a range of spatial scales. Such effects include the consequences of human activities on the spatial patterning and dynamics of ecological communities and wildlife habitats.

A major component of the BLM Landscape Approach is the Rapid Ecoregional Assessment (REA) program. REAs identify important ecosystems and determine where these resources are at risk from development, climate change, wildfire, invasive species, and other environmental stressors that can affect the integrity of ecological systems. Development of methods to quantify landscape intactness or condition is a primary goal of the REAs. Such information is crucial for establishing regional strategies and identifying areas that have potential for conservation, restoration, or development.

Since 2010, BLM has initiated or completed 15 REAs, with additional assessments planned for the near future. By design, the initial REA guidelines allowed considerable flexibility to address local information needs and to foster innovation. Federal and state agencies and nongovernmental organizations provided guidance on appropriate and relevant assessment methods. They also provided vital feedback on the successes and challenges encountered in conducting the REAs and applying the results to management decisions.

Building on the lessons learned from completed or current REAs, the BLM, in partnership with the U.S. Geological Survey, will perform systematic comparisons of REA methods to identify the most promising suite of landscape-level analysis tools. In addition, the BLM and USGS will develop practical applications that demonstrate how to incorporate assessment information to address existing management issues, such as cumulative effects of proposed management actions, as required by the National Environmental Policy Act. 
The outcome of these efforts will be a set of comprehensive technical guidance documents for conducting and applying broad-scale assessments. The guidance documents are intended to identify scientifically defensible methods, promote consistency and transparency in management decisions at multiple scales, and demonstrate how information from regional assessments can be applied within and across jurisdictions. Continued partnerships with multiple governmental and nongovernmental organizations are essential for identifying common information needs, relevant assessment methods to meet those needs, and management applications. This set of guidance documents is expected to benefit natural resource managers, contribute to the development of the BLM Landscape Approach, and support the objectives of the DOI Landscape Strategy.

\section{Technical Guidance for Broad-Scale Assessments}

The primary components of the proposed technical guidance documents include (1) the assessment scoping process, (2) a broad-scale assessment framework, (3) geospatial analysis methods and approaches, and (4) integration of the BLM Landscape Approach into natural resource management.

\section{The Assessment Scoping Process}

The scoping process identifies and prioritizes the management issues, species or ecological communities, and risks or stressors, to be addressed. This includes development of the ecological foundation needed to conduct a geospatial assessment. To ensure the most relevant and scientifically

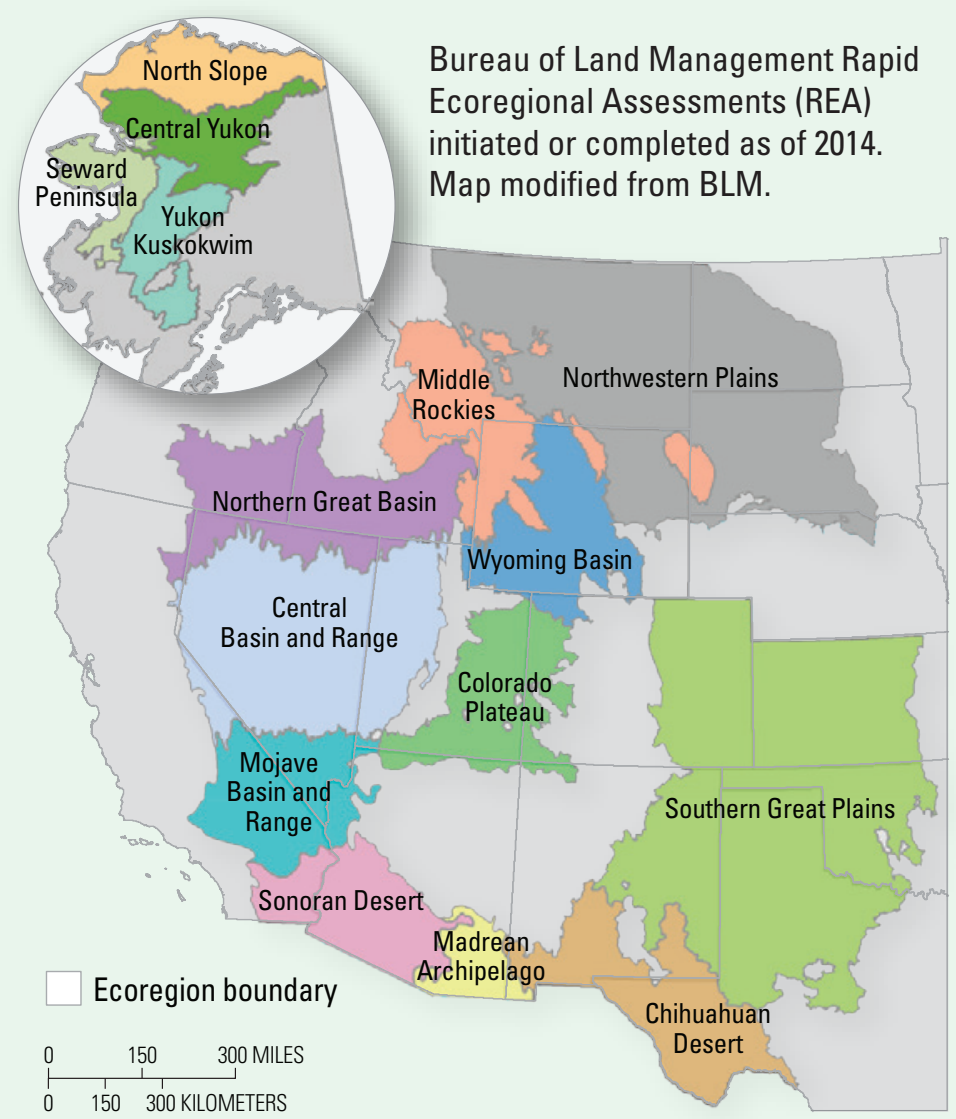

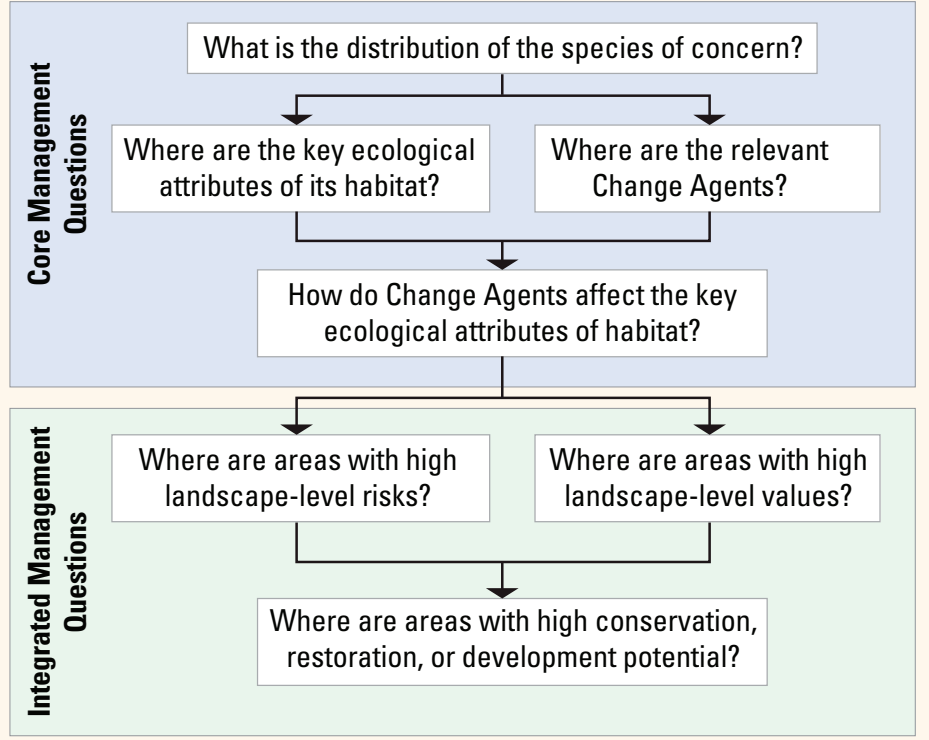

Example of an assessment framework for the Wyoming Basin Rapid Ecoregional Assessment. Change Agents such as development, invasive species, fire, and climate change, are defined as risks or stressors to natural systems.

robust products are developed, additional guidelines will be useful for prioritizing assessment components and products. In particular, the use of selection criteria for identifying and prioritizing regional ecological resources will foster transparency and help agencies and stakeholders meet their priorities, while providing documentation of the decision process used in establishing priorities for the assessment. Regional assessments require collaboration and mutual learning between land managers and scientists. Land managers have knowledge of the priority information needed for management decisions, whereas scientists can evaluate the feasibility and scientific validity of assessment methods. Typically, clarification of management issues requires multiple opportunities to obtain feedback on proposed methods and preliminary products to address information needs. Such feedback provides proof of concept and demonstrates the relevance to end users, thereby improving acceptance and integration into decisionmaking.

\section{A Broad-Scale Assessment Framework}

An assessment framework can be beneficial by providing a clear and concise overview of the assessment process. The framework would identify a set of general management and conservation issues applicable to broad-scale assessments, include a suite of common datasets and methods, and generate products that can be used across multiple regions and jurisdictions. The assessment framework can also clarify the workflow and establish templates for documenting and organizing the assessment components and methods. Such a framework will promote consistency across jurisdictions and help improve understanding of relevant management issues, yet allow flexibility to address local information needs. To enhance communication, the framework will provide clear definitions of terms and concepts relevant to regional assessments. 


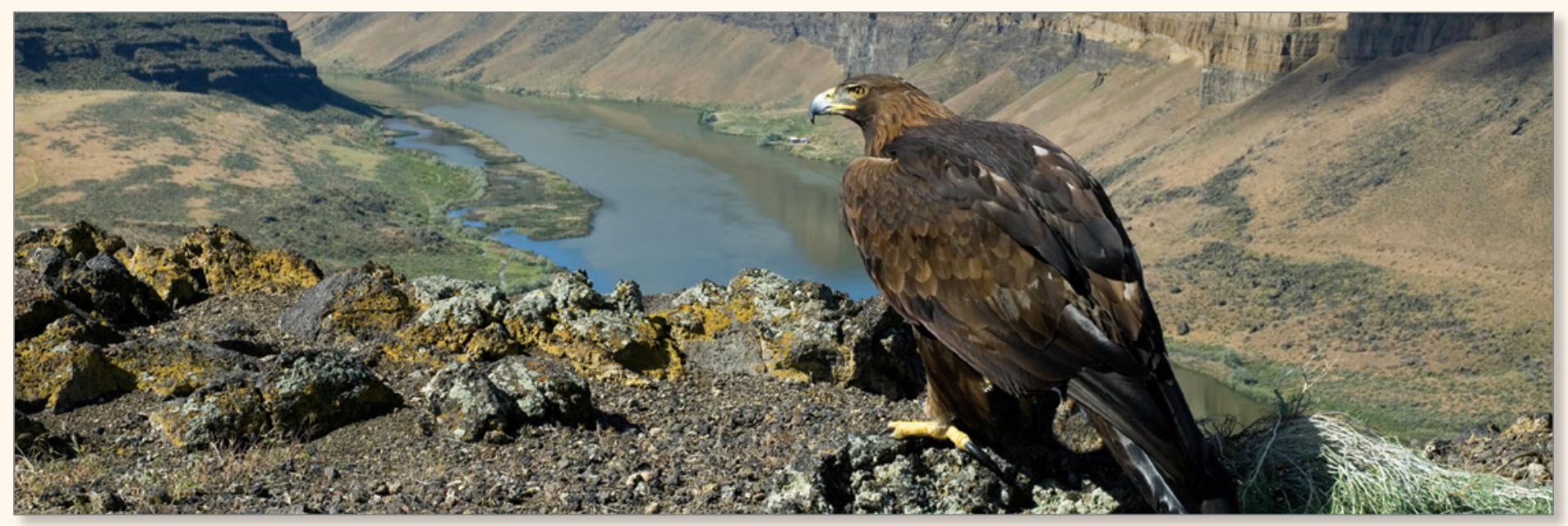

Golden eagle overlooking the Snake River Gorge, Idaho. Photo by Aldis Garsvo, Mountain Post-Digital Imaging.

\section{Geospatial Analysis Methods and Approaches}

A suite of standard approaches for REAs and other broadscale assessments would encourage consistency among ecoregions, while allowing flexibility to address regional management priorities. For example, this could include a set of geospatial analyses that quantify landscape intactness or condition. Scientists with applied expertise in summarizing and modeling at broad spatial scales will be invited to evaluate methods and approaches for use in regional assessments. The development of additional standardized indices, such as an index of ecological integrity, could improve consistency and facilitate comparisons across ecoregion boundaries.

To facilitate multiscale decisionmaking, the guidance would identify appropriate scales of analysis for REAs. In addition, clarification of the accuracy and resolution of source data and results will help to ensure that assessment products are applied at appropriate spatial scales. Because there are substantial data limitations for most ecological resources and risks, management decisions can benefit from improved understanding of how such uncertainty affects our ability to evaluate current conditions and develop realistic future scenarios.

\section{Integrating the Landscape Approach into Natural Resource Management}

Technical assistance, guidance, and support are needed for managers interested in using multiscale information in planning or decisions. Examples of REA applications for developing Resource Management Plans and project-level evaluations can provide guidance on the use of REAs. Initial guidance and test applications of REA data will help land managers incorporate broad multiscale information into planning and management decisions. Expanding the scales of information used for decisions will help managers move beyond the current projectlevel focus of analyses to address issues that span broad spatial scales and administrative boundaries.
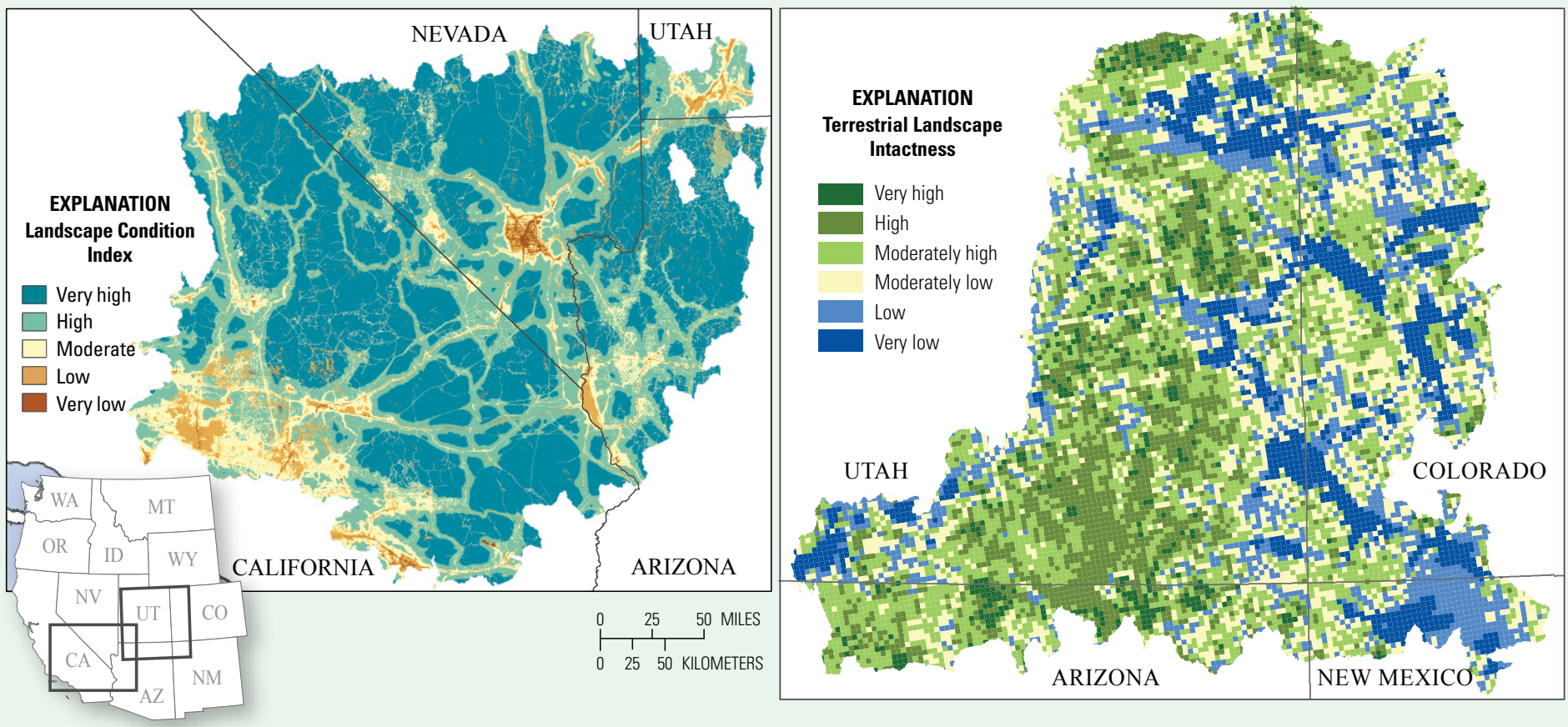

Indices of Landscape Intactness or Condition used for Rapid Ecoregional Assessments. Left panel: the Mojave Basin and Range ecoregion (map modified from NatureServe); Right panel: the Colorado Plateau ecoregion (map modified from Conservation Biology Institute). 


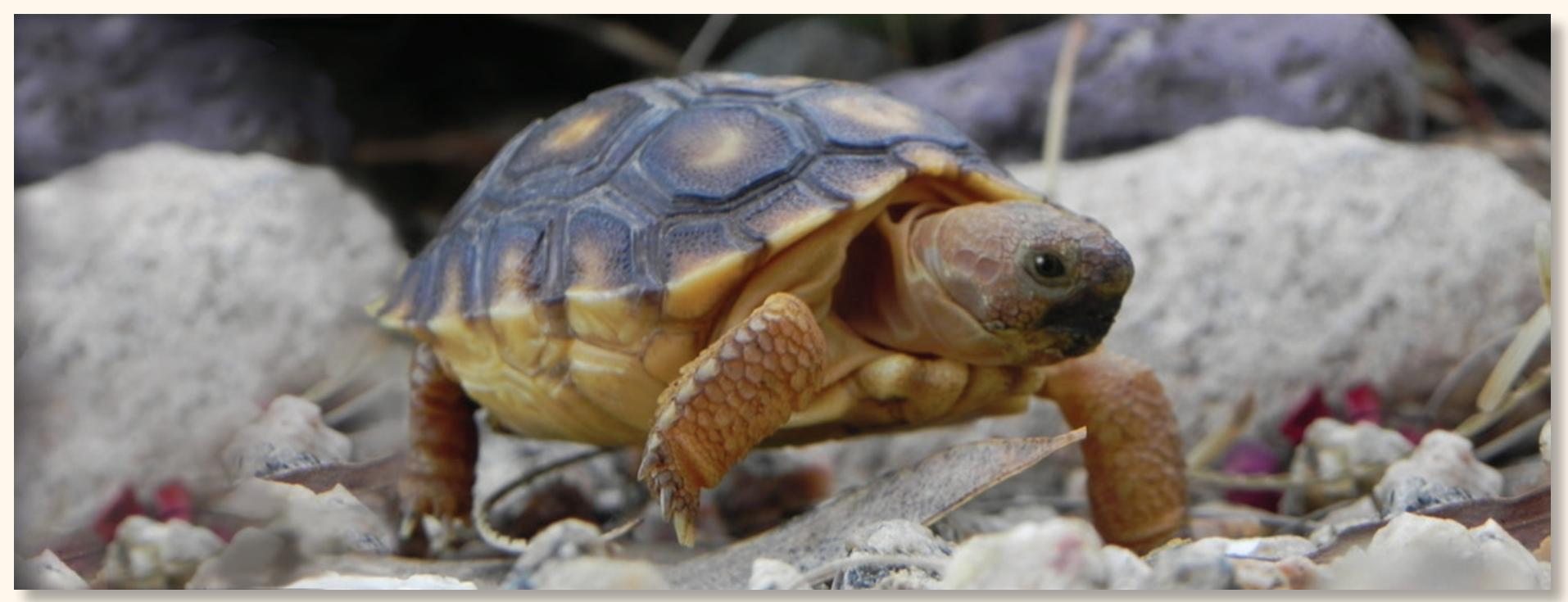

Sonoran desert tortoise in Arizona. Photograph from U.S. Fish and Wildlife Service.

\section{In Conclusion}

The U.S. Department of the Interior's (DOI) Landscape Strategy aims to establish a common landscape-scale approach among the DOI bureaus to ensure consistent policies and practices and more effectively balance development activities with conservation of natural resources. The Bureau of Land Management (BLM) Landscape Approach, the Rapid Ecoregional Assessments, and the proposed technical guidance documents for conducting and applying broadscale assessments directly support a collaborative process that specifically addresses four desired outcomes of the DOI Landscape Strategy, as outlined below.

\section{Geospatial Assessments}

The development of a geospatial information system is needed for identifying existing and potential conservation priorities as well as development opportunities. The information system includes geospatial analysis and decision-support tools and guidelines to facilitate application at appropriate spatial scales.

\section{Landscape-Level Strategies}

Geospatial tools and data are essential for developing landscape-level strategies that encompass the three-step hierarchy to avoid, minimize, and compensate for adverse impacts from major development activities including energy and infrastructure, minerals, and water resources development.

\section{Compensatory Mitigation Programs}

Accessible and transparent multiscale information is critical to developing landscape-level strategic goals. Identification of ecological characteristics that promote ecosystem resilience is a crucial information need for management of the Nation's resources.

\section{Monitoring and Evaluation}

Geospatial systems and data sources are necessary for landscape-scale monitoring and measuring the effectiveness of mitigation strategies. Development of metrics and benchmarks for use in monitoring changes in the condition and landscape patterns of terrestrial and aquatic systems will help inform the application of the DOI Landscape Strategy.

\section{Reference}

Clement, J.P., Belin, Alletta, d'A., Bean, M.J., Boling, T.A., and Lyons, J.R., 2014, A strategy for improving the mitigation policies and practices of The Department of the Interior-A report to the Secretary of the Interior from the Energy and Climate Change Task Force:

Washington, D.C., U.S. Department of the Interior, Energy and Climate Change Task Force, 25 p., http://www.doi. gov/news/upload/Mitigation-Report-to-the-Secretary_ FINAL_04_08_14.pdf.

\section{Additional Information}

For inquiries about the BLM Rapid Ecoregional Assessments and the Landscape Approach, please visit http://www.blm.gov/wo/st/en/prog/more/ Landscape Approach/reas.html.

\section{Contact Information}

Tasha Carr

U.S. Geological Survey

Fort Collins Science Center

(970) 226-9446, carrn@usgs.gov

Zack Bowen

U.S. Geological Survey

Fort Collins Science Center

(970) 226-9218, bowenz@usgs.gov
David Wood

Bureau of Land Management National Operations Center (303) 236-5431, dwood@blm.gov

Travis Haby

Bureau of Land Management Colorado State Office

(303) 239-3714, thaby@blm.gov 